\title{
TYPHOON FRAGILITY ANALYSIS AND CLIMATE CHANGE IMPACT ASSESSMENT OF FILIPINO CULTURAL HERITAGE ASSET ROOFS
}

\author{
G. Sevieri ${ }^{1}$ and C. Galasso ${ }^{2,3}$ \\ ${ }^{1}$ Dept. of Civil, Environmental and Geomatic Engineering, University College London \\ Gower Street, London, WC1E 6BT, United Kingdom \\ g.sevieri@ucl.ac.uk \\ ${ }^{2}$ Dept. of Civil, Environmental and Geomatic Engineering, University College London \\ Gower Street, London, WC1E 6BT, United Kingdom \\ c.galasso@ucl.ac.uk \\ ${ }^{3}$ Scuola Universitaria Superiore (IUSS) Pavia \\ Piazza della Vittoria 15, Pavia, 27100, Italy \\ carmine.galasso@iusspavia.it
}

Keywords: typhoon risk assessment; typhoon risk prioritization; Cultural Heritage; climate change.

\begin{abstract}
Cultural Heritage (CH) assets are especially vulnerable to natural hazards (e.g., earthquake-induced ground shaking, typhoon-induced strong wind, and flooding) due to the lack of hazard-resistant features and to aging-induced extensive structural degradation. These considerations, together with their high historical/cultural value, justify the prioritization/implementation of disaster risk reduction (DRR) and resilience-enhancing strategies for the preservation of such assets.

This paper proposes a probabilistic, simulation-based framework for the derivation of wind fragility relationships for $\mathrm{CH}$ roofs. Roof-panel pullout and pullover failure modes are used to model the progressive failure of the roof system, thus enabling the integration of fastener corrosion effects and load redistribution into the proposed fragility model. Monte-Carlo sampling is used to propagate the uncertainties related to wind-induced demands and roof component (i.e., fasteners and panels) capacities. Climate projections are used to assess the impact of climate change on wind hazard variations, and ultimately on the asset wind risk profile over time.
\end{abstract}

An illustrative application of the proposed procedure is presented with reference to 25 heritage buildings in Iloilo City, Philippines. 


\section{INTRODUCTION}

The 2019 Pacific typhoon season was the costliest ever recorded. It was an above-average year with a total of 17 typhoons recorded in the Philippine Area of Responsibility (PAR, the northwestern Pacific area where the Philippines' national meteorological agency, PAGASA, monitors weather occurrences). The costliest event was the typhoon Kammuri (locally known as Tisoy), which caused PHP 5.9 billion (USD 116 million) of damage to crops and agriculture [1]. In addition, more than 68,000 houses, schools, and other structures were reported destroyed and at least 463,000 were also damaged, including several cultural heritage $(\mathrm{CH})$ assets. Various studies available in the scientific literature discuss how climate change is going to affect the frequency and intensity of future tropical cyclones in the Philippines [2, 3], with a shift towards stronger storms with an estimated intensity increases of $2-11 \%$ by 2100 , as well as changes in their paths $[4,5]$. This, in turn, will lead to an increase in typhoon-induced economic losses [6].

Typhoon-related economic losses in the Philippines are not just due to the adverse environmental conditions. Rapid population growth along the coast together with highly-vulnerable structures/infrastructure contribute to intensify the typhoon-risk of Filipino buildings [7]. Particularly vulnerable in this sense are $\mathrm{CH}$ asset roofs (i.e., wood frame and light-weight metal sheet, LWMS) because of the general lack of any hazard-resistant design considerations, presence of non-engineered structures/detailing, and material/structural degradation due to aging. In particular, non-engineered $\mathrm{CH}$ roofs have been recognized as the most vulnerable component in the building envelope due to typhoon-induced wind uplift. In addition, $\mathrm{CH}$ assets have a fundamental role for local communities. They contribute to creating citizens' sense of place, which is key to form a community's identity, and to promoting local, sustainable jobs related to cultural tourism - a priority sector in several developing countries.

The Filipino government, as well as other stakeholders, are promoting disaster risk reduction (DRR) strategies to improve the resilience of the country and its built environment. This requires a deep understanding of the risk associated to the built environment as well as its variation over time due to degradation/aging and potential effect of climate change. Several methods for typhoon risk assessment/prioritization at building specific and portfolio level, respectively, are available in the scientific literature (e.g., $[8,9])$. Those adopted for building-specific risk assessment usually rely on refined numerical models and require specific data (e.g., roof geometry, number/location of purlins/fasteners, material properties) to be performed/collected. They allow an analyst to model material degradation as well as uncertainties in the definition of both structural capacity and wind-induced demands but with a high computational cost [10]. However, the required information is hardly available when $\mathrm{CH}$ assets located in developing countries are analysed. High population density, the adaptive reuse of $\mathrm{CH}$ assets for private/commercial activities, and diffused material degradation/lack of any maintenance plan all act as disruptive factors during data collection. On the other hand, scoring-based risk prioritization methods are commonly adopted at portfolio level (i.e., for the assessment of a large number of structures in a given region of interest) $[11,12]$. These approaches require only few data about the assets under investigation, but they do not properly consider the variation of the risk during the time due to climate change and material degradation.

A simplified probabilistic, simulation-based framework for the calculation of typhoon risk for $\mathrm{CH}$ asset roofs in the Philippines is herein proposed to address the above-mentioned gaps. The proposed approach can be used both for risk prioritization at portfolio level and for preliminary risk assessment at building specific level. In fact, by considering a simplified geometry of the roof, the proposed method allows corrosion of fasteners and LWMS as well as fastener 
failure progression to be explicitly modelled with relatively low computational cost and requiring only few basic data about the structure.

The proposed procedure is tested in this study on $25 \mathrm{CH}$ assets in Iloilo city, Philippines, which is an important heritage hub for tourism in the Philippines. It is one of the most highly urbanized cities of the south-eastern tip of Panay island in the Philippines [13] and also capital city of the province. Fine examples of historic luxury buildings constructed in the first half of the 20th century during the American colonization can be found in the historic street Calle Real [14].

\section{FILIPINO CULTURAL HERITAGE ASSETS}

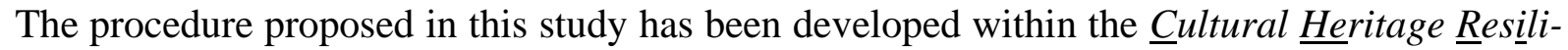

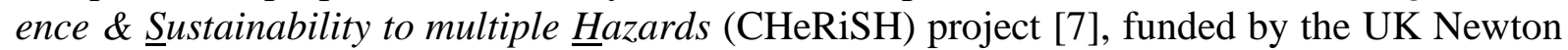
Fund. This project aims to develop a multi-level risk and resilience assessment framework for $\mathrm{CH}$ assets in the Philippines exposed to multiple natural hazards.

The definition of $\mathrm{CH}$ assets is usually based on both tangible (e.g., architectural/ historical value) and intangible (e.g., socio-cultural factors) criteria [15]. However, the Filipino law considers only the building year of construction as the main criterion for the eligibility of a structure as $\mathrm{CH}$ asset [16]. Structures which are at least fifty years old can be declared to be a "Heritage House", so that fairly recent reinforced concrete (RC) frame-type structures and unreinforced masonry (URM) buildings are often part of the Filipino $\mathrm{CH}$ portfolio.

The twenty-five $\mathrm{CH}$ assets analysed in this study (Figure 1) have been surveyed during a field trip in Iloilo City, Philippines, in July 2019 by a research group composed of members from the University College London (UCL, United Kingdom), the De La Salle University (DLSU, Philippines) and Central Philippines University (CPU, Philippines) [7].

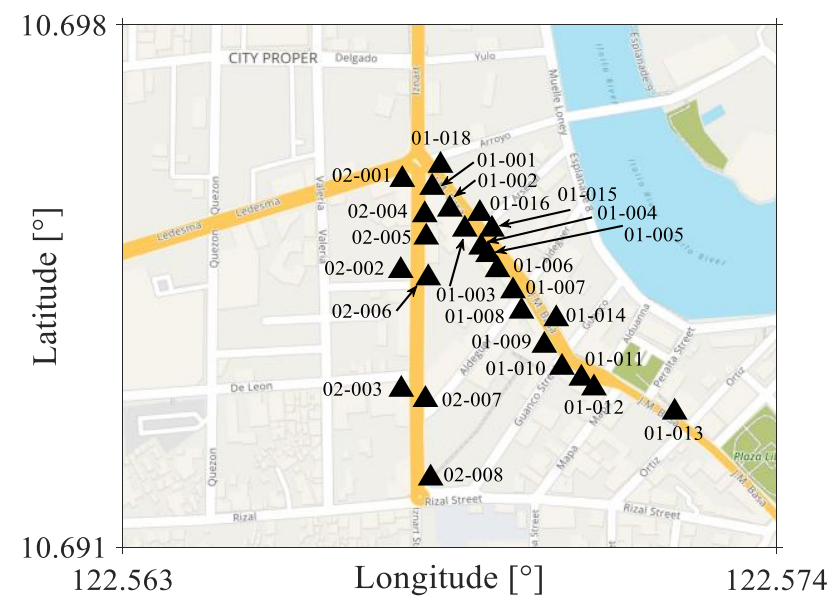

Figure 1: Surveyed CH buildings in Iloilo city, Philippines.

The surveyed $\mathrm{CH}$ portfolio is composed of $24 \mathrm{RC}$ structures and one URM building date back to the first half of the 20th century. Most of them are two-story, plan-regular buildings and part of construction blocks with different shapes (e.g., triangular, rectangular) and compositions (i.e., a block can be the result of building aggregation during the time, or not).

Nineteen $\mathrm{CH}$ roofs out of twenty-five are made of timber frames with LWMS and metal fasteners (i.e., screws or nails). This represents the most common and vulnerable Filipino $\mathrm{CH}$ roof typology, and then it is the focus of the present study. Post-event surveys in the Philippines highlight that most economic losses in high-wind hazard areas are due to the breach of the building envelope [17]. This includes roof panel uplift, roof-to-wall connection failure and roof system damage, among others. Once the roof is damaged or even collapsed, walls lose lateral 
supports and the global stability of the construction is heavily compromised. The local capacity of fasteners and LWMS clearly play a fundamental role in the determination of the global capacity of the roof. Corrosion phenomena, which can affect the strength of both fasteners and LWMS, must then be considered in the typhoon-risk quantification both at building specific and portfolio level. As shown in Figure 2, most of the surveyed $\mathrm{CH}$ roofs were characterised by diffused and heterogeneous corrosion levels [7].
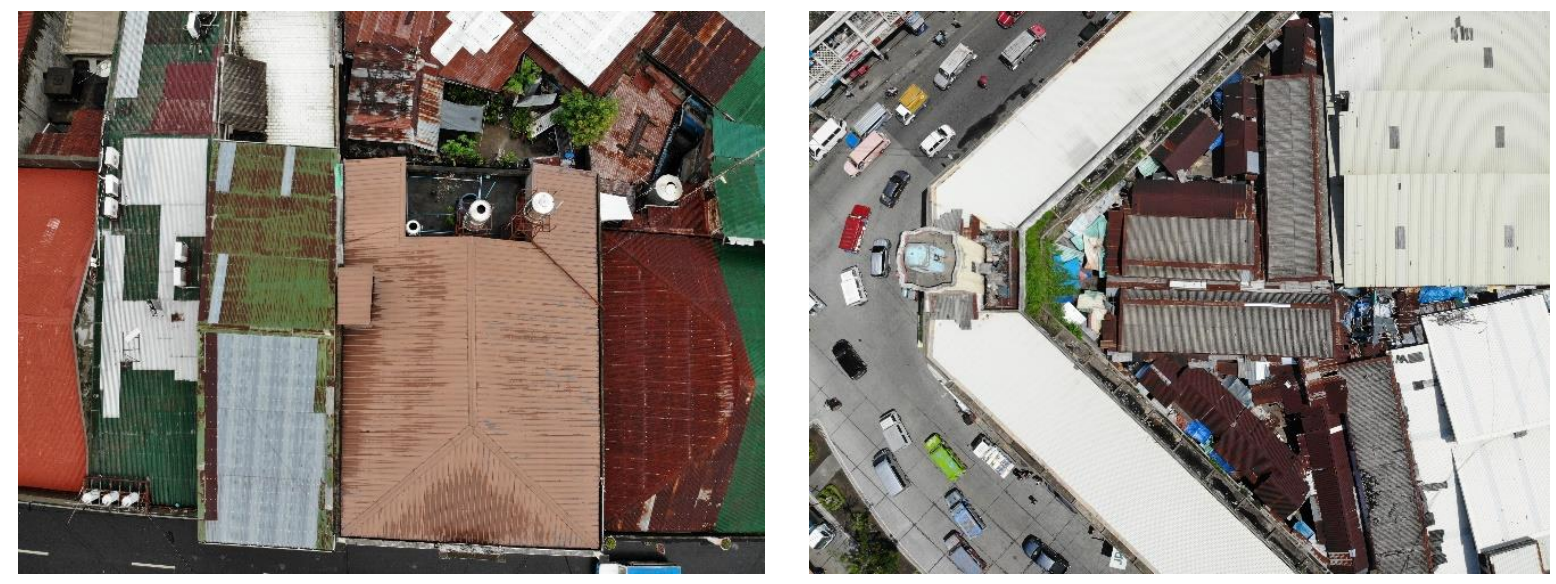

Figure 2: Two samples of Filipino $\mathrm{CH}$ roofs.

\section{TYPHOON RISK ASSESSMENT FOR FILIPINO CULTURAL HERITAGE ASSET ROOFS AND CLIMATE CHANGE IMPACT}

\subsection{Typhoon risk assessment framework}

In this study, Performance-Based Wind Engineering (PBWE) [18] is used as the conceptual framework to define the typhoon risk of $\mathrm{CH}$ asset roofs. In the context of PBWE, the performance of a structure/structural component is assessed through the probabilistic description of a set of decision variables, $D V \mathrm{~s}$ [19]. Each $D V$ is a quantitative proxy for the specific structural performance/damage in terms of metrics of interest for various stakeholders and/or the society in general, e.g., repair cost, downtime, and people affected (casualties/injuries). Once an intensity measure, $I M$ (stochastically describing the hazard intensity at a site of interest), a relevant engineering demand parameter, EDP (synthetically expressing the structural response to wind loads), and a damage-measure parameter, $D M$ (quantifying the structural damage due to wind load in relation to the considered performances and $E D P$ ) are defined, risk can be computed as the mean annual frequency (MAF) (or annual probability) of exceeding a specified value in terms of a relevant $D V$,

$$
\lambda[D V]=\iiint G[D V \mid D M] d G[D M \mid E D P] d G[E D P \mid I M]|d \lambda[I M]| .
$$

In the previous equation $\lambda[\cdot]$ is the mean annual rate of exceedance, while $G[\cdot]$ indicates the complementary cumulative probability distribution function (CCDF) [19].

In this study, the 3-sec gust speed $(v)$ at $10 \mathrm{~m}$ height in open terrain [20] is used as $I M$ while the ratio between damaged LWMS and their total number $R_{\text {damage }}$ is used as $D M$. In this way, the term $d G[D M \mid I M]$ in Equation 1 can be directly derived (as discussed in the following), rather than using $d G[D M \mid E D P] d G[E D P \mid I M]$.

Damage-to-loss (or consequence) models [21], which describe the relationship between $D M$ and $D V$, are then needed to derive $G[D V \mid D M]$. Since no damage-to-loss models are specifically available for Filipino buildings, those developed by the Federal Emergency Management 
Agency (FEMA, 2014) [22] in terms of direct repair cost for residential buildings in the USA are used in this study. This assumption is somehow justified by the fact that the prescriptions included in the Filipino building codes [19] are fully consistent with the recommendations of US building codes [7], across the years. Moreover, the damage-to-loss curves reported in Figure 3 are defined in terms of percentage of building replacement value rather than in absolute terms. Hence, even if this specific aspect will require more investigation in future studies, it still allows one to illustrate/test the validity of the proposed procedure and to obtain loss results for relative comparisons/risk prioritization exercises for the selected case-study portfolio.

The damage-to-loss curves adopted in this study consider direct repair costs associated to roof covering, roof framing and content. It is worth noting that the damage-to-loss curves presented in this section represents the expected loss $L$ given $R_{\text {damage }}$, that is $\mathbb{E}\left[L \mid R_{\text {damage }}\right]$.

Details of the proposed fragility analysis framework and the approach to model climate change impact on wind hazard are presented in the next two sections.

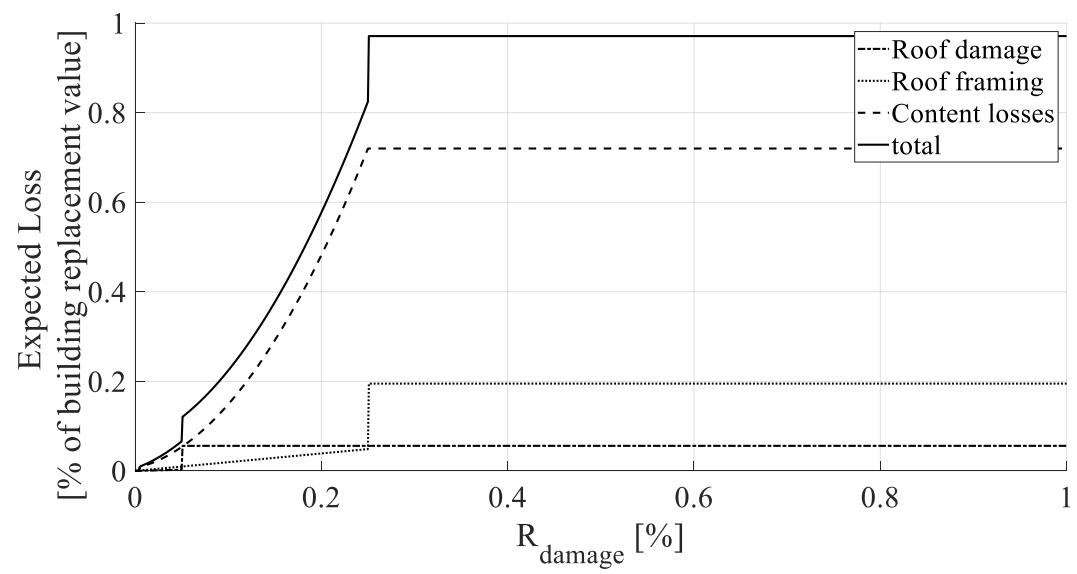

Figure 3: Damage-to-loss curves adopted in this study.

\subsection{Impact of climate change on wind hazard}

One of the specific objectives of this study is to investigate climate change impact on the typhoon risk assessment outputs for Filipino $\mathrm{CH}$ roofs. Climate change is leading to a rise in the temperature of the world's oceans. As their surface temperature increases, oceans provide more energy to convert into tropical cyclones [23]. This is the thermodynamic phenomenon due to climate change that will cause the globally averaged intensity of tropical cyclones to shift towards stronger storms, from being a category 3 (severe tropical storm) to a category 4 (typhoon) by the end of the 21 st century. Not only the intensity of tropical storm is going to be affected by climate change, but also their frequencies, paths and velocities [5].

These variations of the environmental conditions may affect the wind hazard of the country and ultimately the wind risk profile of building roofs. The Type I (Gumbel) distribution is typically adopted in the scientific literature (e.g., Garciano et al., 2005 [24]), and in structural codes (e.g., the National Structural Code of the Philippines, NSCP, 2015 [20]) to model probabilistically the 3-sec gust speed $(v)$ at $10 \mathrm{~m}$ height in open terrain. Climate change effects can be incorporated in the hazard model by modifying the cumulative distribution function (CDF) of the 3-sec gust speed, $\mathrm{F}_{v}(v, t)$, through a function $\gamma_{\text {mean }}(t)$ expressing the time-dependent percentage change in the considered gust wind speed [10], 


$$
\mathrm{F}_{v}(v, t)=\exp \left(-\exp \left(-\left(\frac{\frac{v}{1+\frac{\gamma \operatorname{mean}(t)}{100}}-v_{g}}{\sigma_{g}}\right)\right)\right)
$$

In the previous equation, $v_{g}$ and $\sigma_{g}$ are the location and scale parameters of the CDF, respectively. In Iloilo City, where the case-study buildings considered in this paper are located, these parameters can be assumed as $v_{g}=25.21 \mathrm{~m} / \mathrm{s}$ and $\sigma_{g}=5.75 \mathrm{~m} / \mathrm{s}$ [24]. Recent studies assume a time-dependent linear change in wind speed $\left(\gamma_{\text {mean }}(t)\right)$ and discuss how the use of different functions does not really affect the the wind risk profile [10, 23]. The projected changes in wind speed over the next 50 years is assumed equal to 4\%; this climate scenario is in agreement to the studies available in the scientific literature for similar geographical locations [25].

\section{PROPOSED FRAGILITY MODEL}

\subsection{Overview}

The fragility model proposed in this study is based on a simplified geometry of the roof, which is divided into $N_{m s}$ LWMS, each of which is supported by a constant number of purlins $\left(N_{p}\right)$ and connected through a constant number of fasteners $\left(N_{f}\right)$. LWMS are also assumed not interacting with each other, thus allowing the parallelization of the procedure and a further reduction of the computational burden. Only a few information about the roof are thus needed to perform the fragility analysis, namely: number of LWMS, number of purlins, number of fasteners, distance between purlins $\left(d_{p}\right)$, fastener typology/geometry, LWMS typology/geometry and dead load $(D)$. Once the roof geometry is defined, the limit state function for a given damage state, $g(R, Q)$ (i.e., $R$ is the component capacity, while $Q$ is the wind-induced demand), is derived at fastener level in order to facilitate the integration of failure progression and degradation into the fragility model.

Specifically, when the number of fasteners failing under a given load condition reaches a specific threshold, treated as random variable as well, the LWMS is assumed to fail. Only refined numerical models can properly consider all the factors affecting such a threshold value, such as wind direction, location of the failed fasteners and wind pressure distribution. However, in this study a triangular probability distribution bounded by $10 \%$ and $80 \%$ (the average is $33.3 \%$ ) is adopted for the definition of the threshold, as proposed in [27]. Once the safety of each LWMS is checked, $R_{\text {damage }}$ is calculated as ratio of failed LWMS over $N_{m s}$. This procedure is repeated varying the wind speed $v$ needed for the definition of $Q$.

Monte Carlo sampling is used to propagate the considered uncertainties. Once a wind-speed value $v$ is selected, the uplift loads $W$ are randomly generated for each fastener of each LWMS. For the same elements, pullout and pullover capacities are randomly generated as well (as discussed in the following). A corrosion model is implemented to reduce the resisting sections of fasteners and LWMS over time, thus reducing the capacity $R$. The starting degradation level is treated as random variable to consider the heterogeneity of the 'health' state of different metal sheets as observed during the field trip. 


\subsection{Wind load}

Assuming that LWMS, purlins and fasteners can be considered as components and claddings $(\mathrm{C} \& \mathrm{C})$, the uplift wind load $W\left(\mathrm{~N} / \mathrm{m}^{2}\right)$ is defined according to the American Society of Civil Engineers (ASCE 7-10, 2010) [28] and NSCP (2015) [19], that is

$$
W=q_{h}\left(G C_{p}-G C_{p i}\right) \text {. }
$$

In the previous equation, $q_{h}\left(\mathrm{~N} / \mathrm{m}^{2}\right)$ is the velocity pressure evaluated at the mean roof height of $h$; $G$ is the gust factor; $C_{p}$ (NSCP 2015 Figures 207E.4-2A to 207E.4-7) is the external pressure coefficient; and $C_{p i}$ (NSCP 2015 Table 207A.11-1) is the internal pressure coefficient. In both codes, $q_{h}$ is evaluated as:

$$
q_{h}=0.613 K_{h} K_{z t} K_{d} v^{2},
$$

where $K_{h}$ (NSCP 2015 Table 207E.3-1) is an exposure factor accounting for the terrain exposure condition; $K_{z t}$ is a topography factor; and $K_{d}$ (NSCP 2015 Table 207A.6-1) is a wind directionality factor accounting for the reduced probability of unfavourable building orientation and wind direction.

In this study, the parameter needed for the definition of the wind load $W$ are treated as random variables in order to properly account for the uncertainties (Tables 1 and 2).

Table 1: Statistical model of the wind load parameters.

\begin{tabular}{llllll}
\hline $\begin{array}{l}\text { Parame- } \\
\text { ters }\end{array}$ & Category & Mean & $\begin{array}{l}\text { Coefficient of Varia- } \\
\text { tions }(\mathrm{CoV})\end{array}$ & $\begin{array}{l}\text { Statistical } \\
\text { model }\end{array}$ & Reference \\
\hline$G C_{p}$ & See Table 2 & Normal & \\
$G C_{p i}$ & Partially enclosed & 0.46 & 0.33 & Normal & Ellingwood and Tekie, \\
$K_{h}$ & Exposure B $(0-$ & 0.71 & 0.19 & Normal & 1999 [29] \\
$K_{d}$ & $9.1 \mathrm{~m})$ & 0.89 & 0.16 & Normal & \\
$K_{z t}$ & & \multicolumn{2}{c}{ Deterministic $(=1)$} & & \\
\hline
\end{tabular}

Table 2: Statistics of the gust pressure coefficient $G C_{p}$.

\begin{tabular}{lllllllll}
\hline Metal sheet panel position & Mean & Coefficient of Variations $(\mathrm{CoV})$ & Reference \\
\hline (Wind from all directions) & & & & \\
\end{tabular}

\subsection{Dead and total loads}

The value of the dead load $D$ needed for the calculation of the demand $Q$ depends on the weights of roof panel material and the roof system. This load counteracts the effect of wind uplift, thus contributing to stabilize the roof and increase its resistance. In this study, the dead load is modelled as a deterministic value equal to $0.2 \mathrm{kN} / \mathrm{m}^{2}$ and assumed to remain constant in time (added weight due to re-roofing, if any, is not considered here). 


\subsection{Uplift resistance}

The uplift failure of the system fastener-LWMS is governed by two main mechanisms: pullout and pullover failure modes. The resistance $R$ mainly depends on the fastener typology (i.e., screws or nails), material strengths as well as the geometry of the structural system (e.g., distance between fasteners, distance between purlins). If the forces due to the wind uplift act parallel to the length of the fasteners and perpendicular to the holding members, the nominal pullover resistance per screw and nail $\left(P_{n, \text { over }}\right.$ in $\left.\mathrm{N}\right)$ is computed as

$$
P_{n, \text { over }}=1.5 t d_{w} F_{u 1} \text {, }
$$

Where, in the case of screws, $t(\mathrm{~mm})$ is the thickness of the member in contact with the screw head, $d_{w}(\mathrm{~mm})$ is the larger of the diameter of the washer and the screw head and $F_{u 1}$ $(\mathrm{MPa})$ is the ultimate tensile strength of the member in contact with screw head or washer. Whereas, in the case of nails, $d_{w}$ is the diameter of the nail head.

The definition of the pullout resistance for screws $\left(P_{n, \text { out,screw }}\right.$ in $\left.\mathrm{N}\right)$ is based on the design criteria provided by the NSCP (2015),

$$
P_{n, \text { out,screw }}=0.85 t_{c} d F_{u 2},
$$

where $t_{c}(\mathrm{~mm})$ is the lesser of the depth of penetration and thickness of the element not in contact with the screw head, $d(\mathrm{~mm})$ is the nominal screw diameter, and $F_{u 2}(\mathrm{MPa})$ is the ultimate tensile strength of the member not in contact with the screw head or washer.

In the case the roof structure consists of wood purlins, nails are generally used as fasteners. In this case, according to the National Design Specification (NDS) for Wood Construction (AWC, 2017) [31], the pullout capacity for single smooth shank nail used as wood-to-wood and metal-to-wood connections ( $P_{\text {out,nail }}$ in $\mathrm{N}$ ) can be expressed as

$$
P_{\text {out,nail }}=K_{w} G_{\text {out }}^{5 / 2} d_{s} P \text {, }
$$

where, $G_{\text {out }}$ is the specific gravity of the wood based on oven-dry weight, $d_{s}(\mathrm{~mm})$ is the shank diameter of the nail, $P(\mathrm{~mm})$ is the penetration of the nail in the member holding the nail point, and $K_{w}$ is a constant having a value of 9.515, which is converted from the original value of 1380 (in empirical unit) for SI unit consistency.

The parameters needed for the definition of the roof panel capacity are treated as random variables to properly account for the epistemic uncertainties involved in the fragility calculation and to 'balance' the simplified geometry of the proposed model. In particular, the geometric parameters of the resisting elements (i.e., $d_{w}, t_{c}, d, d_{s}, P$ ) are considered normally distributed with mean values equal to the nominal values assumed during the analysis or measured during field surveys. More specifically, $4 \mathrm{~d}$ and $8 \mathrm{~d}$ fasteners (i.e., nominal diameters equal to 2.9 and $3.3 \mathrm{~mm}$, respectively) are usually found for such a roof typology [25, 32]. Therefore, if observed data are not available, fastener typology and size can be randomly generated. Whereas, the coefficients of variations are derived from studies related to Filipino roofs available in the scientific literature $[8,33]$. Table 3 summarises the statistical model for the pullout/pullover capacity adopted in this study.

Table 3: Statistical model of the capacity parameters.

\begin{tabular}{llll}
\hline Parameters & Mean & Coefficient of Variations (COV) & Statistical model \\
\hline$t$ & $0.79 \mathrm{~mm}$ & 0.1 & Normal \\
$d_{w}$ & Nominal or assumed value & 0.05 & Normal \\
$d$ & Nominal or assumed value & 0.05 & Normal \\
$d_{s}$ & $20 \%$ of $d$ & 0.025 & Normal \\
$P$ & Nominal or assumed value & 0.25 & Normal \\
$F_{u 1}$ & $147 \mathrm{MPa}$ & 0.35 & Log Normal \\
\hline
\end{tabular}




\begin{tabular}{llll}
\hline$F_{u 2}$ & $215 \mathrm{MPa}$ & 0.1 & Log Normal \\
$t_{c}$ & Nominal or assumed value & 0.025 & Normal \\
$G_{\text {out }}$ & Nominal or assumed value & 0.25 & Normal \\
\hline
\end{tabular}

\subsection{Load redistribution and corrosion effects}

Load redistribution among fasteners and corrosion effects are key issue to derive system-level capacity. When a fastener fails, its load is redistributed among the closest resisting elements until the equilibrium is achieved. $90 \%$ of the load of the failed fastener is redistributed between those located on parallel purlins, while the remaining $10 \%$ goes to fasteners which are on the same purlin. In the proposed procedure, the load is redistributed until the equilibrium is achieved each time that a fastener fails and if the metal sheet is still safe [10]. Once the load is redistributed to other fasteners, these can fail and a rapid damage progression can occur.

Corrosion affects the effective section of fasteners and LWMS, thus reducing the uplift resistance of the roof panels over time. The corrosion model adopted in this study is the one proposed by Nguyen et al. (2013) [34], which considers two types of corrosions: embedded and atmospheric. The former is generated by corrosive agents that are within the surrounding wood, such as wood acidity and timber moisture content. Only parts inside the wood, such as the shank of nails are affected. Whereas, the atmospheric corrosion is due to corrosive agents within the surrounding air, such as airborne salinity and airborne pollution agents. The parts of the cladding exposed to the air, such as the heads of nails and screws as well as the LWMS surfaces, are affected by this type of corrosion. The parameters needed for the definition of the corrosion model are derived from the environmental data provided by PAGASA [35].

\section{RESULTS}

\subsection{Fragility analysis}

The fragility analysis has been carried out for all the $19 \mathrm{CH}$ assets previously introduced by varying the gust wind speed $v$ from 0 to $100 \mathrm{~m} / \mathrm{s}$ with $2 \mathrm{~m} / \mathrm{s}$ steps and by increasing the corrosion depths by considering 10-year steps from 0 to 50 years (i.e., observation year, y). Moreover, ten-thousand steps are considered within the Monte Carlo sampling, while the log-normal CDF is used to fit the analysis results by applying the maximum likelihood estimation (MLE) method [36]. For the sake of clarity, only the fragility curves for building with ID '01-001' and '02003 ' (Figure 4) are discussed in this section. The building '01-001' has 2.6-mm shank diameter screws with a 500-mm spacing, while the building '02-003' has 2-mm shank diameter nails with 250-mm spacing. When the fragility curves are derived for year 0 , so without increasing the initial corrosion depths, the two $\mathrm{CH}$ asset roofs show similar fragility relationships. When time passes, the corrosion affects more the roof '02-003' (Figure 4b) than the roof '01-001' (Figure 4a); in fact, the distance among fragility curves is larger in Figure 4b. This is mainly due to the fact that nails are affected by both embedded and atmospheric corrosion, because of the use of wood purlins. Whereas, screws are generally subjected to only atmospheric corrosion, which usually achieves value smaller than the embedded one [34]. In general, the fragility curves derived in this study show that $\mathrm{CH}$ roofs with nails as fasteners are more sensitive to corrosion than the screw ones. 


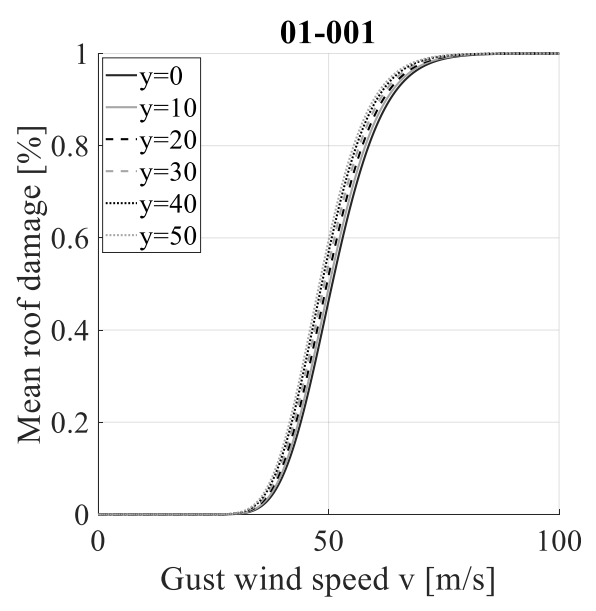

a)

Figure 4: Fragility curves derived for different observation years (y): a) building 01-001 (screws), b) building 02-003 (nails).

\subsection{Risk assessment}

The results of the fragility analysis are then used to calculate the expected loss in terms of percentage of building replacement value as a function of the mean annual frequency (MAF) of the 3-sec gust speed $v$ (i.e., simplified loss curves are derived, Figure 5). The calculation is repeated by varying the reference year from 0 to 50 years to account for both corrosion effects and climate change impact.

Loss curves calculated considering the reference year equal to 0 are very close, thus reflecting the result obtained for the fragility curves. The variation of the reference year affects more the roof '02-003' (nails) than the '01-001' one (screws). This is mainly due to the corrosion effect rather than the climate change, as explained before.

It is worth noting that the loss curves presented in this section are derived considering the expected values of damage-to-loss curves $\mathbb{E}\left[L \mid R_{\text {damage }}\right]$ (section 3.1). A comprehensive discussion of this problem would require considering the uncertainty related to the damage-to-loss curves, that means to consider $p\left[L \mid R_{\text {damage }}\right]$.

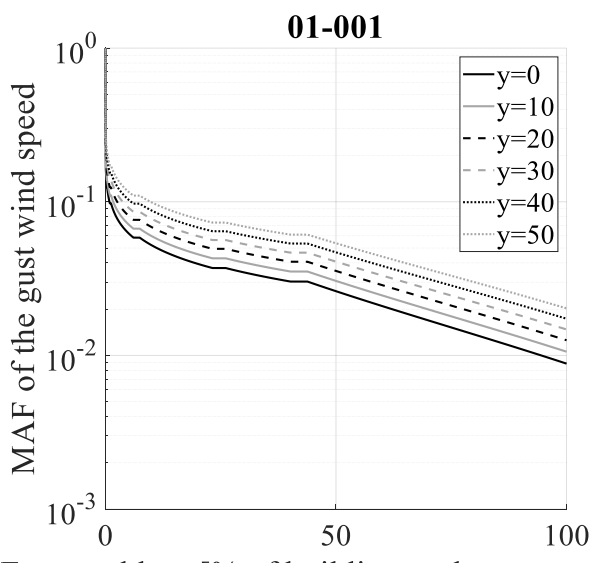
a)
Expected loss [\% of building replacement value]

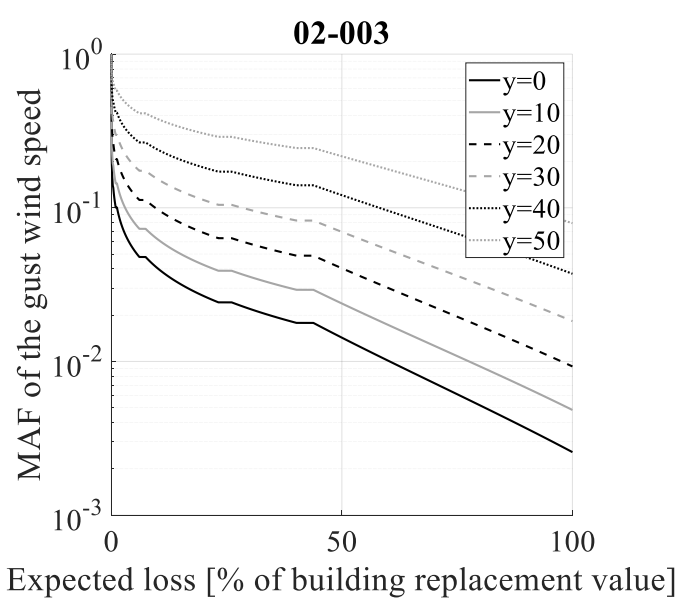

b)

Figure 5: Loss curves: a) building 01-001 (screws), b) building 02-003 (nails). 


\subsection{Risk prioritization}

The previous results are finally used to calculate the expected annual loss (EAL) [37] for each $\mathrm{CH}$ asset by varying the reference year. The resulting EAL are then used to prioritize the building portfolio by proposing a typhoon risk prioritization index $I_{T R}$. The index related to the $k$-th $\mathrm{CH}$ assets considering the $i$-th reference year is defined as,

$$
I_{T R, i, k}=\frac{(100-1)}{\left(\mathrm{EAL}_{\max , i}-\mathrm{EAL}_{\min , i}\right)}\left(\mathrm{EAL}_{i, k}-\mathrm{EAL}_{\min , i}\right)+1,
$$

where, $\mathrm{EAL}_{\mathrm{max}, i}$ and $\mathrm{EAL}_{\mathrm{min}, i}$ are the maximum and minimum $\mathrm{EAL}$ within the analysed portfolio. The resulting indices are arbitrarily categorized in three groups, respectively "green, yellow and red tags" by defining two thresholds. As a proof of concept, in this study the thresholds are selected to be equal to $33 \%$ and $66 \%$ for the calculated typhoon risk index. The results reported in Figure 6 show that the variation of the reference year of analysis leads to a small variation of the prioritization index. This fact indicates that even if corrosion and climate change affect the risk analysis at building-specific scale (previous section), the initial conditions of the analysed $\mathrm{CH}$ assets are more important for the definition of the typhoon risk prioritization scheme.

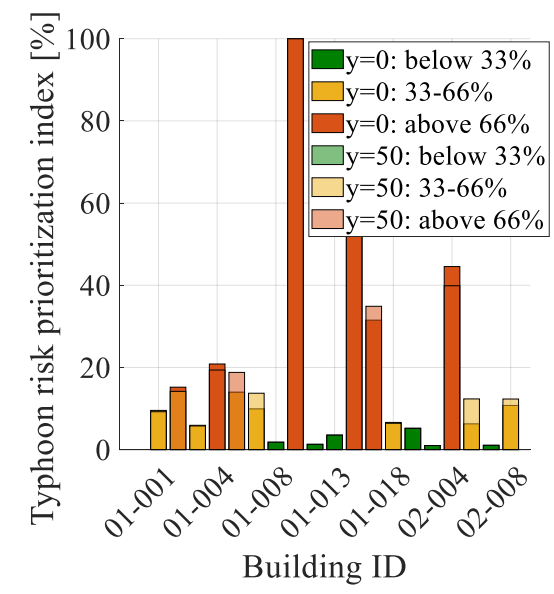

Figure 6: Typhoon risk prioritization index.

\section{CONCLUSIONS}

The Philippines is particularly prone to natural hazards, such as typhoons and earthquakes. Last catastrophic events have emphasized that the Filipino built environment is highly vulnerable to typhoons. This is likely to be worsened in the future because of the impact of climate change on typhoon intensities, frequencies and paths. Among the most vulnerable buildings, $\mathrm{CH}$ assets deserve special attention because of their intangible value for local communities, and their fundamental role in sustaining cultural tourism. Hence, typhoon risk assessment methods at building specific level and typhoon risk prioritization schemes at portfolio level, suitably defined for $\mathrm{CH}$ assets, are fundamental to prioritize disaster risk reduction and resilience-enhancing strategies.

This paper has presented a simulation-based approach for $\mathrm{CH}$ roof fragility derivation in which roof panel pullout and pullover failure mechanisms, corrosion effects and load redistribution (after fastener failure) have been explicitly modelled. Filipino $\mathrm{CH}$ asset roofs are made of timber frames and light-weight metal sheet (LWMS) with steel screws and nails used as fasteners; this structural typology has been the main focus of the study. A simplified model for the roof geometry, at the base of the proposed approach, has enabled 1) to reduce the required computational burden for fragility assessment; and 2) to probabilistically model 
capacities/demands. The proper balance between refinement level and uncertainty consideration/propagation makes the proposed approach especially suitable for both risk prioritization and preliminary risk assessment at building specific level.

The analysis of $25 \mathrm{CH}$ assets in Iloilo City, Philippines, has shown the feasibility of the proposed approach and has enabled the evaluation of the impact of the climate change on the risk assessment at building specific level and on the prioritization scheme. The results of the analysis have revealed that corrosion may strongly affect the fragility results for the considered $\mathrm{CH}$ roofs. Therefore, given the lack of maintenance activities in several developed countries corrosion around the world, corrosion effect must be considered in the typhoon fragility/risk assessment. Results of the analysis have also shown that climate change affects more the risk assessment estimates at building specific level than the prioritization scheme.

\section{ACKNOWLEDGMENTS}

This study was performed in the framework of the "CHeRiSH: Cultural Heritage Resilience \& Sustainability to multiple Hazards" project funded by the UK British Council. The University of the Philippines Visayas (UPV), the Central Philippine University (CPU), and the De La Salle University (DLSU), Manila, are acknowledged for the technical support during the fieldwork.

\section{REFERENCES}

[1] Republic of the Philippines - National Disaster Risk Reduction and Management Council, Situational Report No.19 Regarding Response Actions and Effects of Typhoon "TISOY" (I.N. KAMMURI). Camp Aguinaldo, Quezon City, Philippines, 2019.

[2] T.R. Knutson, J.L. McBride, J. Chan, K. Emanuel, G. Holland, C. Landsea, I. Held, J.P. Kossin, A.K. Srivastava, M. Sugi. Tropical cyclones and climate change. Nat. Geosci. 3, 157-163, 2010.

[3] K. Emanuel, Global warming effects on U.S. hurricane damage. Weather. Clim. Soc. 3, 261-268, 2011.

[4] W.N. Holden, S.J. Marshall, Climate change and typhoons in the Philippines: Extreme weather events in the anthropocene, Integrating Disaster Science and Management: Global Case Studies in Mitigation and Recovery, Elsevier Inc., pp. 407- 421, 2018.

[5] W. Mei, S.P. Xie, F. Primeau, J.C. Mc Williams, C. Pasquero, Northwestern Pacific typhoon intensity controlled by changes in ocean temperatures. Sci. Adv., 4, 1- 8, 2015.

[6] E. Strobl, The impact of typhoons on economic activity in the Philippines: evidence from nightlight intensity (No. 589), ADB economics working paper series, 2019.

[7] G. Sevieri, C. Galasso, D. D’Ayala, R. De Jesus, A. Oreta, M.E.D.A. Grio, R. Ibabao, A multi-hazard risk prioritization framework for cultural heritage assets. Nat. Hazards Earth Syst. Sci., in review, 2020.

[8] B. Song, C. Galasso, L. Garciano, WARP^2: Wind Assessment of Roofs to Pullout \& Pullover for Priority Cultural Heritage Structures in the Philippines. Proceedings of the 13th International Conference on Applications of Statistics and Probability in Civil Engineering (ICASP13). Seoul, South Korea, 2019.

[9] H. Masoomi, M. R. Ameri, J.W. Van De Lindt, Wind Performance Enhancement Strategies for Residential Wood-Frame Buildings. J. Perform. Constr. Facil. 32, 2018. 
[10] M. G. Stewart, Climate change impact assessment of metal-clad buildings subject to extreme wind loading in non-cyclonic regions, Sustain. Resilient Infrastruct, 1, 32- 45, 2016.

[11] R. Gentile, C. Galasso, Y. Idris, I. Rusydy, E. Meilianda, From rapid visual survey to multi-hazard risk prioritisation and numerical fragility of school buildings in Banda Aceh, Indonesia. Natural Hazards and Earth System Sciences Discussions, 19, 1365-1386, 2019.

[12] G. Pita, J. P. Pinelli, K. Gurley, J. Mitrani-Reiser. State of the art of hurricane vulnerability estimation methods: A review, Nat Hazards Rev., 16, 2, 2015.

[13] Philippine Statistics Autorithy, Census of Population 2015: "Region VI (Western Visayas)". Total Population by Province, City, Municipality and Barangay. Report 2016-070, 2016.

[14] Iloilo City Cultural Heritage Conservation Council (ICCHCC), Implementing Rules and Regulations for the Downtown Central Business District (CBD) Heritage Zone. Iloilo City, Philippines, 2010.

[15] United Nations Educational, Scientific and Cultural Organization (UNESCO), Operational Guidelines for the Implementation of the World Heritage Convention, Report WHC.17/01, 2017.

[16] Republic Act No. 10066, National Cultural Heritage Act of 2009, 2009.

[17] Q. Yang, R. Gao, F. Bai, T. Li, Y. Tamura, Damage to buildings and structures due to recent devastating wind hazards in East Asia. Nat Hazards., 92, 1321-1353, 2018.

[18] M. Ciampoli, F. Petrini, G. Augusti, Performance-Based Wind Engineering: Towards a general procedure, Struct Saf., 33, 367-378, 2011.

[19] J. Moehle, G. G. Deierlein, A framework methodology for performance-based earthquake engineering. Proceedings of 13th World Conference on Earthquake Engineering, Vancouver, BC, Canada, 3812-4, 2004.

[20] Association of structural engineers of the Philippines, National Structural Code of the Philippines, Manila, 2015.

[21] A. J. Kappos, G. Panagopoulos, C. Panagiotopoulos, G. Penelis, A hybrid method for the vulnerability assessment of R/Cand URM buildings. Bull Earthq Eng., 4, 391-413, 2006.

[22] Federal emergency management agency (FEMA) - Mitigation division, Multi-hazard loss estimation methodology - hurricane model, Hazus-MH 2.1 Technical manual, Washington, D.C., 2014.

[23] J. B. Elsner, J. P. Kossin, T. H. Jagger, The increasing intensity of the strongest tropical cyclones, Nature, 455, 7209, 92-95, 2008.

[24] L. Garciano, M. Hoshiya, O. Maruyama, Development of a regional map of extreme wind speeds in the Philippines, Struct Eng Eng., 22, 1, 15-26, 2005.

[25] M. G. Stewart, J. D. Ginger, D. J. Henderson, P. C. Ryan, Fragility and climate impact assessment of contemporary housing roof sheeting failure due to extreme wind, Eng Struct., 171, 464-475, 2018.

[26] A. Silang, S. N. Uy, J. M. Dado, F. A. Cruz, G. Narisma, N. Libatique, G. Tangonan, Wind Energy Projection for the Philippines Based on Climate Change Modeling, Energy Procedia., 52, 26-37, 2014. 
[27] K. M. C. Konthesingha, M. G. Stewart, P. Ryan, J. Ginger, D. Henderson, Reliability based vulnerability modelling of metal-clad industrial buildings to extreme wind loading for cyclonic regions. J Wind Eng Ind Aerodyn., 147, 176-85, 2015.

[28] American Society of Civil Engineers (ASCE), ASCE 7-10. Minimum Design Loads for Buildings and Other Structures (ASCE/SEI 7-10), American Society of Civil Engineers, Reston, VA, 2010.

[29] B. R. Ellingwood, P. B. Tekie, Wind load statistics for probability-based structural design, J Struct Eng., 125, 4, 453-463, 1999.

[30] K. H. Lee, D. V.Rosowsky, Fragility assessment for roof sheathing failure in high wind regions, Eng Struct., 27, 857-868, 2005.

[31] American Wood Council (AWC), National Design Specification for Wood Construction. Leesburg, VA, 2017.

[32] Y. Dong, Y. Li, Reliability of Roof Panels in Coastal Areas Considering Effects of Climate Change and Embedded Corrosion of Metal Fasteners. ASCE-ASME J Risk Uncertain Eng Syst Part A Civ Eng., 2, 1, 2016.

[33] I. P. R. Alvarez, J. A. M. Colobong, C. Q. Decal, A. B. S. Tan, Pull-Out and Pull-Over Failure Probability of Residential House Roofs due to Extreme Wind Speeds: a Case Study in Malate, Metro Manila, BSc thesis, De La Salle University, 2013.

[34] M. N. Nguyen, R. H. Leicester, C. H. Wang, G. C. Foliente, Corrosion effects in the structural design of metal fasteners for timber construction, Struct Infrastruct Eng., 9, 3, 275-284, 2013.

[35] Philippine Atmospheric Geophysical and Astronomical Services Administration. PAGASA website. http://bagong.pagasa.dost.gov.ph/. Published 2020.

[36] J. W. Baker. Efficient analytical fragility function fitting using dynamic structural analysis. Earthq Spectra, 31, 1, 579-599, 2015.

[37] K. M. Solberg, R. P. Dhakal, J. B. Mander, B. A. Bradley, Computational and rapid expected annual loss estimation methodologies for structures, Earthq Eng Struct Dyn., 37, 1, 81-101, 2007. 